\title{
The Introduction of Generic Substitution in Australia and Its Inspiration for China
}

\author{
Feng Chang \\ School of International Pharmaceutical Business \\ China Pharmaceutical University \\ Nanjing, China 211198 \\ Qiang Xia \\ School of International Pharmaceutical Business \\ China Pharmaceutical University \\ Nanjing, China 211198
}

\author{
Jianyun Zhang* \\ School of International Pharmaceutical Business \\ China Pharmaceutical University \\ Nanjing, China 211198 \\ *Corresponding Author \\ Penglei Cui \\ School of International Pharmaceutical Business \\ China Pharmaceutical University \\ Nanjing, China 211198
}

\begin{abstract}
The aim of this article is to enhance understanding of how the cost-containment strategy of generic substitution is working, the effectiveness of generic substitution in Australia. It has been shown effective with regard to lowering the price of medicines. Generic substitution is a commonly used costcontainment strategy meant to control pharmaceutical expenditure without compromising health objectives. It has provided experiences and references to China.
\end{abstract}

Keywords-Australia; generic; substitution; pharmaceutical expense

\section{INTRODUCTION}

The application of generic drugs is proved to be one of the methods to reduce expenditure of pharmaceutical expenses and increase the coverage rate of essential drugs. On February 9, 2017, General Office of the State Council issued Opinions on Further Reforming and Improving the Policies for the Production, Circulation and Use of Pharmaceuticals (GBF [2017] No.13), to pass generic drugs with consistency evaluation and bring it into the list of pharmaceuticals interchangeable with original drugs. The Opinions on Consistency Evaluation of Quality and Efficacy of Generic Drugs (GBF (2016) No. 8) issued before has great significance on improving the integral level of pharmaceutical industry in our country and guaranteeing the safety and effectiveness of generic drugs. The proposition of policies such as the efficient implementation of consistency evaluation on generic drugs and the introduction of generic drugs to the list of pharmaceuticals interchangeable with original drugs provides opportunities to improve quality of generic drugs of our country, promote generic drugs to undertake the responsibilities and obligations of substituting original drugs and popularize and use generic drugs in our country. The generic substitution system in Australia is analyzed, and operation mechanism and implementation effects of generic substitution policy are concluded, in order to provide references for use of generic drugs, the establishment or implementation of related policies.

\section{INTRODUCTION TO GENERIC SUBSTITUTION}

Australia implements national health insurance system, which is divided into Medical Benefits Scheme and Pharmaceutical Benefits Scheme (PBS). Australian Government compensates drugs through PBS, which has implemented since 1948 to provide drugs for patients in clinics and communities. Australian communities implement the policy of separation of clinic from pharmacy. Community health service institutions don't establish pharmacy. Patients purchase drugs by physician's prescription; inpatients enjoy free medical service and they don't need to pay for drugs separately. PBS covers about 90 percent of pharmaceutical market in Australia.

In order to control pharmaceutical expense and relieve patients' burden, Australia has formally implemented the policy of Generic Substitution ${ }^{1}$ since December 1, 1994. For drugs in PBS compensation list, unless patients refuse or the prescription indicates it cannot be substituted, the pharmacists have rights to substitute with generic drugs. The implementation of generic substitution policy decreases the use of brand premium drugs in PBS list and effectively controls the pharmaceutical expense.

Australian Government issued new policies on generic substitution in May 2015. When safety and equivalence are proved, it is allowed to substitute Bio-similar with original drugs. Besides, the management of bio-similar in PBS is the same with other generic drugs with bioequivalence and has no perquisite.

Refer to generic substitution. 


\section{OPERATION MECHANISM OF GENERIC SUBSTITUTION}

To encourage pharmaceutical substitution, Australian PBS realizes policy objective of pharmaceutical substitution through regulating selection of PBS pharmaceutical list, drug price setting, pharmaceutical reimbursement and pharmacists' prescription dispensing.

\section{A. PBS Selection and Management}

In Australia, pharmaceuticals can get compensation of national health insurance when they are listed in PBS compensation.
After being approved listing and registering, Therapeutic Goods Administration (TGA) can apply for PBAC to list in PBS. PBAC consists of ESC and DUSC to evaluate clinical and economic benefits of pharmaceuticals and budget effects and submit report before holding PBAC meeting; ATAGI is responsible for consultation of vaccines. PBPA negotiates the price of pharmaceuticals to be listed in PBS in "Fig. 1". In the end, the results are submitted to Department of Health in Australia. Pharmaceuticals are formally listed in PBS after approval. [1]

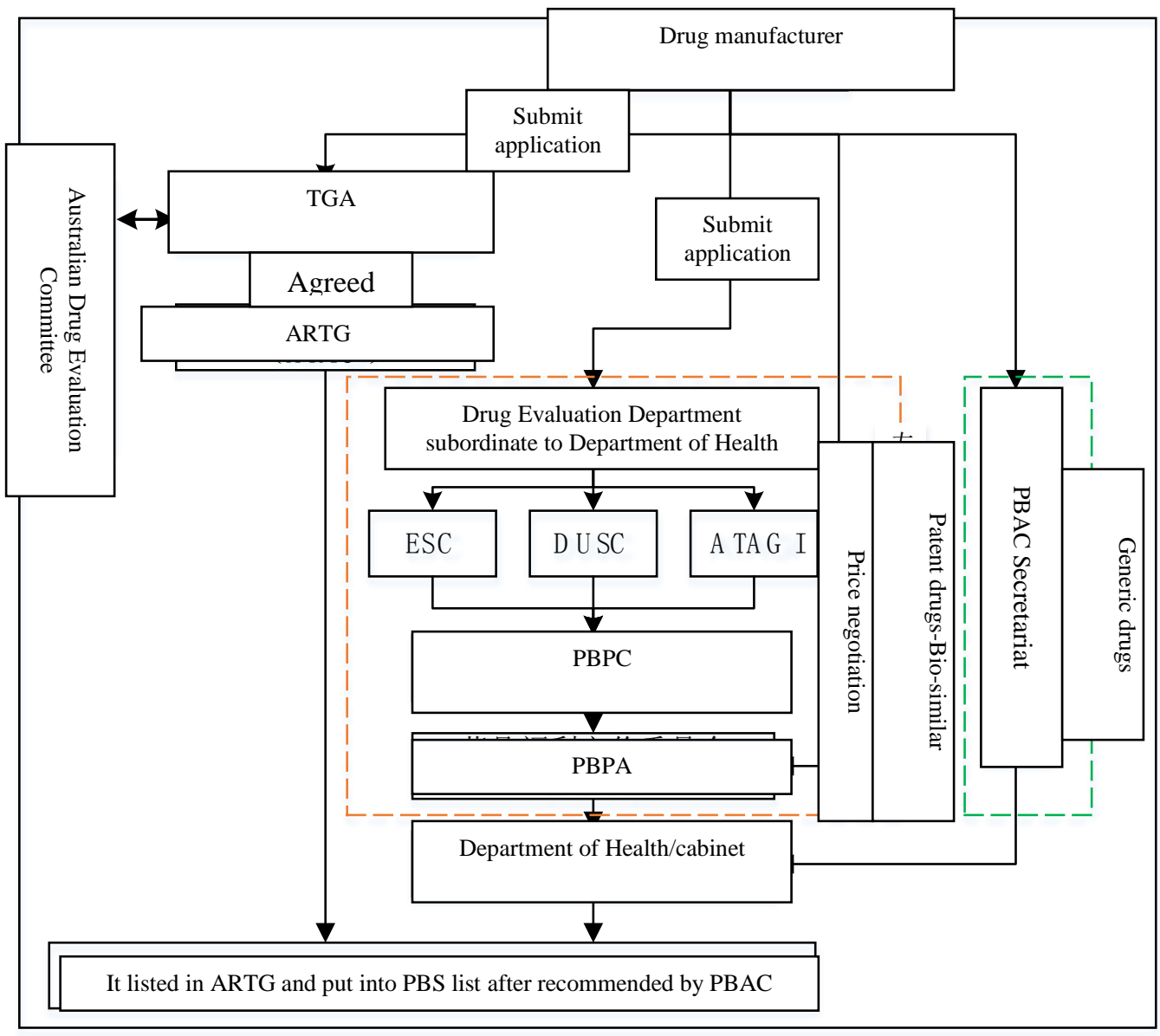

Fig. 1. The flow of pharmaceuticals to be listed in PBS.

Listing generic drugs in PBS doesn't need to be discussed through PBAC meeting. When the patents expire, drug manufacturers apply for TGA to let generic drugs appear on the market. After registering, they can directly submit materials to PBAC Secretariat. It can be listed in PBS after getting approval of the Department of Health. It effectively accelerates listing generic drugs in PBS.

\section{B. Systematic Management of PBS Pharmaceutical List}

Australia divides pharmaceuticals in PBS list into alternative pharmaceuticals and non-alternative pharmaceuticals.
In order to standardize the management of generic substitution, lower the pharmaceutical expense under the premise of meeting patients' demands, on August 1, 2007, PBS divides pharmaceutical list into Formulary 1 (F1) and Formulary 2 (F2). F1 contains drugs that only have one trade name under generic name and most of them are patent drugs; other drugs excluded from F1 are listed in F2, most are original drugs or generic drugs and each drug has many brands, they belong to interchangeable drugs in "Table I". [2] 
TABLE I. PBS DRUg LIST CLASSIFICATION

\begin{tabular}{|c|l|}
\hline PBS list & \multicolumn{1}{c|}{ Selection criteria } \\
\hline $\boldsymbol{F 1}$ & $\begin{array}{l}\text { 1)Drugs that each dosage form and standard only has one } \\
\text { brand; and } \\
\text { 2) Cannot interchange with other drugs in PBS list }\end{array}$ \\
\hline $\boldsymbol{F 2}$ & $\begin{array}{l}\text { Other drugs excluded from F1, mainly including: } \\
\text { 1)Drugs with many trade names under on generic name } \\
\text { (2) One treatment group has many interchangeable drugs }\end{array}$ \\
\hline
\end{tabular}

For drugs that have been listed in F1, if drugs with bioequivalence to it are also listed in PBS, the drugs will be removed from $\mathrm{F} 1$ and listed in $\mathrm{F} 2$.

\section{PBS Drug Price Regulation}

PBPA regulates price of drugs in PBS list according to exfactory price. The management styles of price of drugs in F1 and F2 are different. In order to lower pharmaceutical expense and promote the market competition of generic drugs, measures are established to lower the price of drugs in F2.

1) Forced price reduction: According to National Health Act 1953, listing the first generic drug in PBS will trigger forced price mechanism. Drugs with patent expiration that have been listed in PBS will be transferred from F1 to F2. The price will lower 16 percent (12.5 percent previously) based on the original price.

Each year has six opportunities to force price adjustment on February 1, April 1, June 1, August 1, October 1 and December 1. If the first generic drug is listed in PBS not on the date of forcing price adjustment, the drugs with patent expiration included in the original PBS list will be forced to lower price on the next price adjustment date.

Forced price reduction is one-off, namely it will happen once. It rapidly benefits patients. Once generic drugs are listed in PBS, patients can purchase drugs with lower price.

2) Price disclosure: To prevent the drug price of actual transaction deviating (lowering than) from PBS drug price, price disclosure mechanism is established to continuously monitor and regularly adjust the price of original drugs or generic drugs. PBS reform in 2007 brought in price disclosure mechanism, which adjusted scope and cycle of drugs related to price disclosure in 2010 and 2014 respectively. At present, all original drugs and generic drugs in F2 must follow the price disclosure mechanism; drug suppliers must regularly and truthfully submit data of market transaction price to Price Disclosure Data Administrator (PDDA), including selling profit, discount and sales volume; adjust price disclosure every six months on April 1 and October 1 yearly. [3]

If Weighted Average Disclosed Price (WADP) calculated according to business volume and discount provided by enterprises is 10 percent lower than approved ex-manufacturer price (AEMP), AEMP is forced to lower to WADP.

In Australia, generic drugs will have specific brand name instead of only having generic name after listing.
In 2015, PBS further adjusted the price disclosure mechanism and improved the way of calculating WADP, namely remove original drugs in calculating WADP. Original drugs with patent expiration still have high market share and seldom discount. After removing the data, WADP will lower, which will promote price reduction. [4]

\section{PBS Drug Compensation Measures}

Australia uses the management mode of "limited price payment". The government sets the price on PBS list, which refers to the purchase price of pharmacy (ex-factory price plus bonus to wholesalers). Health insurance compensates pharmacy according to this price. When patients purchase drugs on PBS list in pharmacy by prescription issued by physician, they directly pay according to the price after compensation. Australian Health Insurance Commission compensates according to records of prescriptions in the pharmacy.

Benchmark Price and Brand Premium are established to encourage people to use generic drugs.

1) Benchmark price: In PBS pharmaceutical compensation, Australia sets the drug with the lowest price under the same generic name (drug manufacturers agree to accept the price) as Benchmark Item, its PBS price as benchmark price. Health insurance compensates the price of drugs in PBS list according to the benchmark price. Other drugs on PBS list will carry out price compensation according to benchmark price.

2) Brand premium: Products with brand premium are often original drugs. If some brand drug and benchmark item have bioequivalence and interchangeability, and drug manufacturers can prove it is superior to benchmark items in clinical and cost effectiveness, it can apply for higher PBS price than benchmark items. The excess is called brand premium. It is the responsibility of patients instead of health insurance to bear the brand premium.

When pharmacists choose generic substitution in drug preparation, patients can refuse generic substitution and choose products with brand premium and bear the brand premium.

On one hand, set benchmark price of compensation, and the pharmaceutical expense is controlled through restricting the level of health insurance compensation; on the other hand, the policy that patients bear the brand premium stimulates them to choose generic substitution.

\section{E. Incentive Policy for Pharmacists' Dispensing}

In Australian health insurance system, pharmacists play distinctly important role in generic substitution. Australian government has taken measures to encourage pharmacists to carry out generic substitution in prescription dispensing.

1) Manage dispensing and infrastructure fees: Australia carries out the reform of bonus to pharmacy to encourage dispensing of generic drugs and promote generic substitution.

When purchasing drugs on PBS list, pharmacy has rights to raise price based on the wholesale price and retail it to 
patients at the retail price and take the price margin as retail revenue in "Fig. 2". The price margin is bonus to the

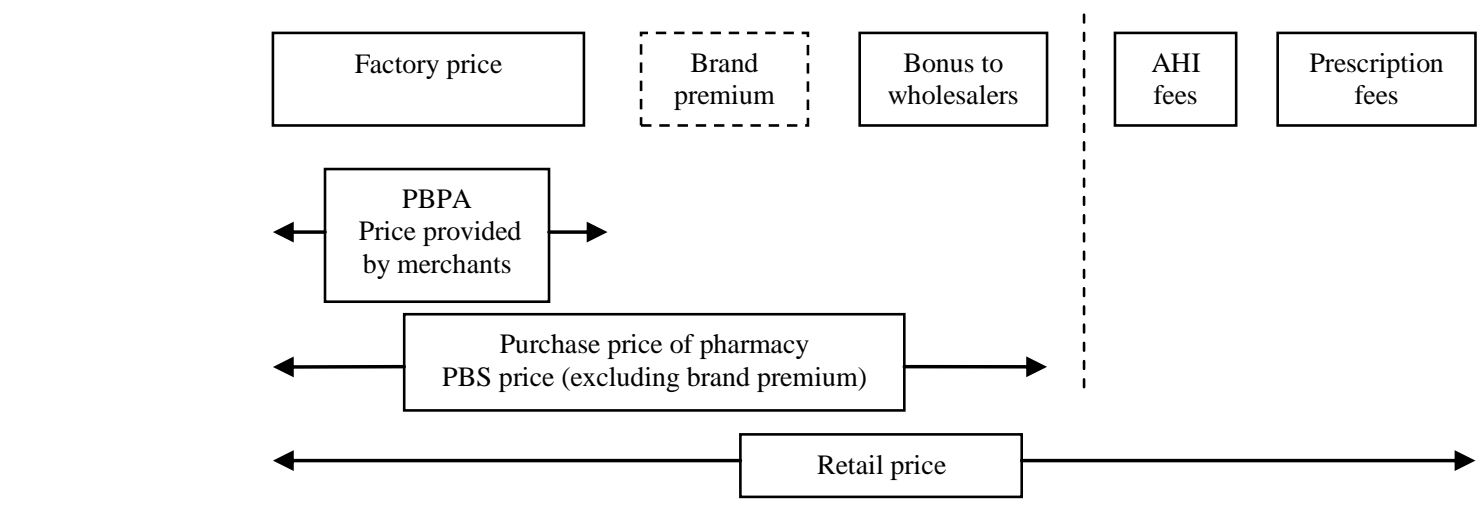

pharmacy.

Fig. 2. Formation of Australian drug price.

Before July 1, 2015, bonus to pharmacy directly related to drug price. Because the market competition of generic drugs is intensifying and measures continuously lower the price of generic drugs, the enthusiasm of pharmacies in choosing generic drugs is dampened. Therefore, in 2015, PBS reformed bonus to pharmacy. AHI fee (Administration, Handling and Infrastructure fee) replaces the previous structure of bonus to pharmacy and separates bonus to pharmacy from drug price in "Table II".

TABLE II. DRUG PRICE AND AHI FEE

\begin{tabular}{|c|l|l|}
\hline No. & Price to Pharmacy, PtP & \multicolumn{1}{|c|}{ AHI fee } \\
\hline $\boldsymbol{1}$ & $\mathrm{PtP}<\$ 180$ & $\$ 3.54$ \\
\hline $\mathbf{2}$ & $\$ 180 \leq \mathrm{PtP} \leq \$ 2089.71$ & $\$ 3.54+3.5 \% *(\mathrm{PtP}-180)$ \\
\hline $\mathbf{3}$ & $\mathrm{PtP}>\$ 2089.71$ & $\$ 70.92$ \\
\hline \multicolumn{2}{|c|}{ Premium-free dispensing incentive: Australian }
\end{tabular}

Government introduced Premium-Free Dispensing Incentive on August 1, 2008. When pharmacists choose generic substitution in dispensing drugs on PBS list, each prescription can receive award of 1.50 Australian Dollars. To further encourage the use of generic drugs, on July 1, 2016, it is adjusted to 1.74 Australian Dollars. Moreover, it will be adjusted yearly according to CPI.

PFDI is the important economic factor to stimulate pharmacists to choose generic substitution in dispensing. [5]

\section{F. Other Measures to Promote Generic Substitution}

1) Boost the market of generic drugs by law: In 2006, Parliament of Australia passed Amendment to Intellectual Property Law, which provides more flexible legal environment for the research and development of generic drugs. Before patents expire, in order to get government review and approval for drug listing, developers of generic drugs can legally use others' patents without the permission of patentees, namely manufacture patented products or use patented method, [6] in order to accelerate the listing of generic drugs after the patent expires.
2) Strengthen publicity to improve biosimilar awareness: The Department of Health has launched Biosimilar Awareness Initiative since May 2015, investing 20 million Australian Dollars to popularize bio-similar for three years (from June 2015 to June 2018), in order to enhance the confidence of physicians, pharmacists and patients in generic drugs and promote the use of it. [7] It is estimated that during 2015 and 2020, the use of bio-similar can save about 88 million Australian Dollars for PBS. [8]

\section{EFFECTS OF PBS GENERIC SUBSTITUTION}

\section{A. Number and Proportion of Generic Drug Prescription}

Generic substitution policy increases the number of generic drug prescription. Statistical results indicate the number of generic drug prescription in PBS has ascended from 37.8 million in 2003 to 13.2 million in 2013 , and the proportion ascends from 54 percent to 80 percent in "Table III". Obviously, the policy formulated by Australian Government to encourage the use of generic drugs is effective. 
TABLE III. Prescriptions of GENERIC Drugs on PBS List and Brand Premium Drugs [9] Data Source: PBAC ANNuAl RePort

\begin{tabular}{|c|c|c|c|c|c|c|c|c|c|c|c|}
\hline $\begin{array}{c}\text { Prescription } \\
\text { Year } \\
\end{array}$ & 2003 & 2004 & 2005 & 2006 & 2007 & 2008 & 2009 & 2010 & 2011 & 2012 & 2013 \\
\hline $\begin{array}{l}\text { Variety of brand } \\
\text { premium drugs }\end{array}$ & 303 & 321 & 335 & 345 & 360 & 353 & 337 & 303 & 295 & 283 & 287 \\
\hline $\begin{array}{l}\text { Arithmetic average } \\
\text { price of brand } \\
\text { premium }\end{array}$ & $\$ 3.06$ & $\$ 2.65$ & $\$ 2.78$ & $\$ 2.76$ & $\$ 2.88$ & $\$ 3.03$ & $\$ 3.29$ & $\$ 3.18$ & $\$ 3.08$ & $\$ 2.84$ & $\$ 2.86$ \\
\hline $\begin{array}{l}\text { Weighted average } \\
\text { price of brand } \\
\text { premium }\end{array}$ & $\$ 1.57$ & $\$ 1.74$ & $\$ 1.77$ & $\$ 1.76$ & $\$ 1.83$ & $\$ 2.10$ & $\$ 2.10$ & $\$ 2.33$ & $\$ 2.44$ & $\$ 2.48$ & $\$ 2.41$ \\
\hline $\begin{array}{c}\text { Price range of brand } \\
\text { premium }\end{array}$ & $\begin{array}{l}\$ 0.06- \\
\$ 79.48\end{array}$ & $\begin{array}{l}\$ 0.06- \\
\$ 79.48\end{array}$ & $\begin{array}{l}\$ 0.06- \\
\$ 79.48\end{array}$ & $\begin{array}{l}\$ 0.06- \\
\$ 79.48\end{array}$ & $\begin{array}{l}\$ 0.09- \\
\$ 76.86\end{array}$ & $\begin{array}{l}\$ 0.08- \\
\$ 76.86\end{array}$ & $\begin{array}{l}\$ 0.08- \\
\$ 76.86\end{array}$ & $\begin{array}{l}\$ 0.08- \\
\$ 75.30\end{array}$ & $\begin{array}{l}\$ 0.08- \\
\$ 72.32\end{array}$ & $\begin{array}{l}\$ 0.44- \\
\$ 13.59\end{array}$ & $\begin{array}{l}\$ 0.44 \\
\$ 13.59\end{array}$ \\
\hline $\begin{array}{c}\text { Number of } \\
\text { prescription with } \\
\text { brand premium drugs } \\
\text { (million) } \\
\end{array}$ & 32.6 & 33.6 & 30.0 & 30.1 & 27.9 & 25.2 & 19.9 & 16.7 & 16.1 & 14.7 & 13.2 \\
\hline $\begin{array}{c}\text { Number of } \\
\text { prescription with drugs } \\
\text { at benchmark price } \\
\text { (million)/percent }\end{array}$ & $\begin{array}{l}37.8 \\
54 \%\end{array}$ & $\begin{array}{l}42.9 \\
56 \%\end{array}$ & $\begin{array}{l}50.5 \% \\
63 \%\end{array}$ & $\begin{array}{l}51.9 \\
63 \%\end{array}$ & $\begin{array}{l}52.7 \\
65 \%\end{array}$ & $\begin{array}{l}53.0 \\
68 \%\end{array}$ & $\begin{array}{l}56.7 \\
74 \%\end{array}$ & $\begin{array}{l}51.2 \\
75 \%\end{array}$ & $\begin{array}{l}52.5 \\
76 \%\end{array}$ & $\begin{array}{l}53.4 \\
78 \%\end{array}$ & $\begin{array}{l}53.9 \\
80 \%\end{array}$ \\
\hline
\end{tabular}

\section{B. Changes of PBS Expense}

Generic substitution slows down the growth of PBS pharmaceutical expense. The all-in cost of PBS drugs from 2003 to 2015 is analyzed in order to explore its variation trend. The statistical graph indicates the growth of all-in cost of PBS drugs from 2003 to 2015 slows down. The comparative growth rates on moving base drop from 9.0 percent, 9.3 percent and 20.0 percent in 2003, 2004, and 2005 respectively to 1.7 percent in 2014 and negative values in 2013 and 2015 . It indicates he measures of generic substitution implemented by Australian Government slow down the growth of PBS expense and saves drug costs.

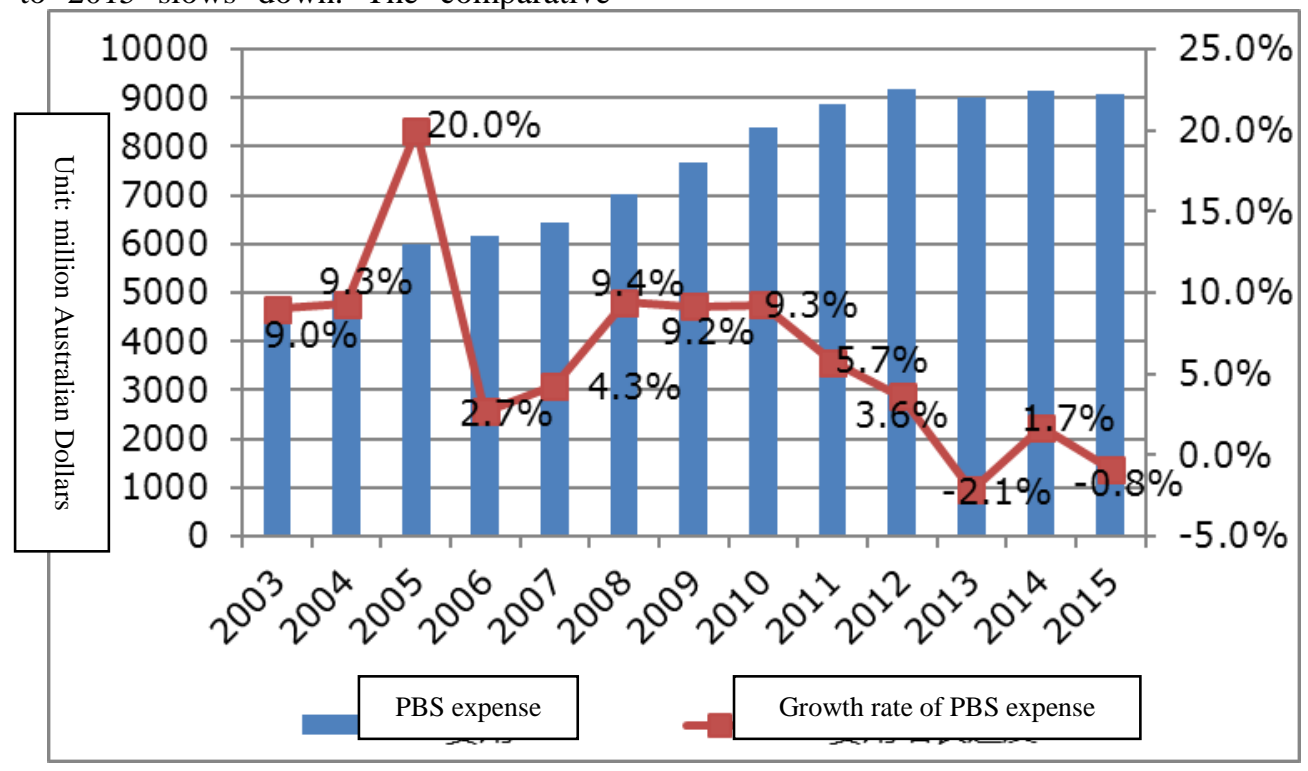

Fig. 3. PBS expense in 2003-2015 and the expense growth rate trend.

\section{CONCLUSION}

With weak economic growth, countries make efforts to control the costs in medical treatment and public health. Using generic drugs to substitute drugs with patent expiration has become the common practice of developed countries to suppress the excessive growth of costs in medical treatment and public health. In recent years, domestic economic growth slows down, the number of insured people saturates and people have increasingly high requirements for health service. How to use the limited medical and health resources to meet medical demands of patients becomes an important issue of
Chinese government. Although Australia and China are different in economic development level and medicine and health environment, the generic substitution policy still provides reference for our country.

First, hold correct attitudes toward generic drugs. The correct attitudes of physicians and pharmacists toward generic drugs are prerequisites to promote generic substitution and the use of generic drugs. Steps should be taken to popularize generic drugs, in order to let patients understand the differences between generic drugs and original drugs and hold correct attitudes toward generic drugs. We can refer to Biosimilar Awareness Initiative launched in Australia and 
invest capitals to popularize among physicians, pharmacists and patients.

Second, make policies of generic substitution. According to Australian generic substitution policy and specific circumstance of pharmaceutical market in China, put generic substitution into trial use, bring generic drugs qualified in quality and price into the list of drugs interchangeable with original drugs and encourage the use of generic drugs.

Third, create the institutional environment of separation of clinic from pharmacy. According to Australian Medical Benefits Scheme and Pharmaceutical Benefits Scheme, the experience in separation of clinic from pharmacy, we can take pilot measures of separation of clinic from pharmacy at different levels in different areas in China according to economic and medical service development in different areas. Meanwhile, strengthen pharmacists' right to speak in prescription dispensing and form the balance mechanism that physicians and pharmacists restrict and supervise mutually. Refer to active policies of PFDI and take corresponding economic measures to stimulate physicians and pharmacists to dispense prescription of generic drugs.

Furthermore, let patients share the expenses in medical security to promote patients to choose generic drugs through economic incentive.

For developing countries that the expenditures for medical care and public health as well as patients' purchasing power are far below than that of developed countries, using generic drugs to substitute expensive original drugs has important significance in welfare economics.

\section{REFERENCES}

[1] Parkinson B. Pharmaceutical Policy in Australia[J]. 2013.

[2] Fu Hongpeng. Achievements of PBS Reform in Australia [J], China Hospital CEO, 2013(8): 80-81

[3] Pharmaceutical Benefits Scheme Price Disclosure Arrangements. Procedural and Operational Guidelines.2014.

[4] Zhao Feili, Wu Jing, Wu Jiuhong. Sustainable Measures of Australian Pharmaceutical Benefit Scheme -Based on 2015 New Round of Reform Scheme [J], China Health Insurance, 2016, (the 4th Issue)

[5] Ding Jinxi, Xiao Huiqiang, Li Wei. Evaluation Research on Generic Substitution System of Public Medical Insurance in AmericaEmpirical Analysis Based on Medicaid Plan [J], Northwest Population Journal, 2015 (5): 101-106

[6] Zhou Heping. New "Springboard" of Generic Drugs in Australia and Enlightenment on Pharmaceutical Enterprises of Our Country [J], Chinese Journal of Pharmaceutics, 2007, (the Second Issue)

[7] Pieter Dylst, Arnold Vulto \& Steven Simoens (2013) Demand-side policies to encourage the use of generic medicines: an overview, Expert Review of Pharmacoeconomics \& Outcomes Research, 13:1, 59-72, DOI: $10.1586 /$ erp.12.83.

[8] Biosimilar awareness initiative project management plan. the department of health.2016. http://www.health.gov.au/internet/main/publishing.nsf/Content/biosimil ar-awareness-initiative.

[9] Pharmaceutical Benefits Pricing Authority - Annual Report.2012-2013. http://www.health.gov.au/internet/main/publishing.nsf/Content/annualreport-1213-toc $\sim 12-13 \mathrm{a} \sim 12-13 \mathrm{a} 2$.

[10] PBS Expenditure and Prescriptions. PBS Information Management Section Pharmaceutical Policy Branch. 2003-2015. 